\title{
O INÍCIO DA HIERARQUIZAÇÃO NO CRISTIANISMO PRIMITIVO NA I CARTA DE CLEMENTE AOS CORÍNTIOS (SÉC. I D.C.)
}

\author{
The beginnings of Hierarchisation in Primitive Christianity in Clement's First \\ Letter to the Corinthians ( $1^{\text {st }}$ century $\left.A D\right)$
}

Amanda Cristina Martins do Nascimento ${ }^{1}$ Monica Selvatici

\begin{abstract}
RESUMO: O presente artigo tem como objetivo discutir o início da hierarquização no cristianismo primitivo através da problematização do caso específico da comunidade coríntia, presente na I Carta de Clemente aos Coríntios. A I Carta de Clemente aos Coríntios é datada pela maioria dos estudiosos de meados da década de 90 d. C. Escrita em Roma por Clemente, além de dar conselhos, o autor intenta manter a unidade entre os membros da ekklesia. $\mathrm{O}$ autor da carta aponta que existe uma insurreição no interior da comunidade, a finalidade do texto é manter a união fraterna dos fiéis coríntios, pois segundo Clemente, as autoridades religiosas instituídas foram depostas por membros mais jovens. Dessa maneira, veremos que a submissão a uma hierarquia era algo que Clemente queria que os fiéis reproduzissem. Sua concepção de ekklesia sob a ótica de uma submissão, obediência e humildade se contrapõe à situação vivida na comunidade de Corinto daquele momento, que, segundo o próprio autor, estava dividida por interesses pessoais.
\end{abstract}

Palavras-chave: cristianismo primitivo, comunidades cristãs, I Clemente, hierarquização.

ABSTRACT: : The present article aims to discuss the beginnings of hierarchisation in early Christianity through the specific case of the Corinthian community, as presented in Clement's First Letter to the Corinthians. Written in Rome, Clement's Letter to the Corinthians is dated by most scholars to the mid-90s, CE. Therein, the author tries, besides giving advice, to maintain unity among the members of the ekklesia. He also points out that there is an insurgence inside the community. The purpose of the text is to maintain fraternal union among Corinthian disciples, because according to Clement, the instituted religious authorities had been deposed by younger members. As a result, we will see that submission to hierarchy was something that Clement wanted the members of the community to reproduce. His understanding of ekklesia from the standpoint of submission, obedience and humility thus contrasts with the situation experienced by the Corinthian community at the time, which, according to the author himself, was divided by personal interests.

Keywords: Early Christianity, Christian communities, I Clement, hierarchisation.

\footnotetext{
${ }^{1}$ Mestre em História Social (UEL), Especialista em Religiões e Religiosidades e Graduada em História pela Universidade Estadual de Londrina. E-mail: amanda.hpuel@gmail.com

2 Doutora em História pela Universidade Estadual de Campinas (UNICAMP). Professora Associada de História Antiga e Medieval do Programa de Pós-graduação em História Social e do Departamento de História da Universidade Estadual de Londrina (UEL). E-mail: mselvatici@ gmail.com
} 


\section{INTRODUÇÃO}

Reflexões científicas sobre o cristianismo primitivo vêm apresentando análises de grande relevância tanto na historiografia sobre o Mundo Antigo como também nos estudos das religiões e religiosidades. Abordagens multidisciplinares a partir de diferentes campos do conhecimento auxiliam na compreensão de fenômenos religiosos, do cotidiano de grupos sociais, dos papéis de gênero dentro de uma nova crença, entre outras relações entre indivíduos e sociedades ao longo da história.

Em trabalhos anteriores, ${ }^{3}$ trabalhamos com a construção das identidades na comunidade coríntia por meio da análise de duas fontes: a I Carta de Paulo aos Coríntios e a $I^{a}$ Carta de Clemente aos Coríntios. Notamos então que no Brasil se encontram poucos trabalhos que examinam Clemente Romano $^{4}$, e, ainda, que o foco dos autores que encontramos incide sobre o discurso de Clemente em relação a aspectos outros que não os de nosso objetivo de pesquisa, como: educação e moral cristã e a vivência da perseguição sofrida pelos fiéis.

Portanto, para esse artigo, optamos por apresentar um estudo acerca do desenvolvimento de uma hierarquização inicial dentro das comunidades cristãs. A nossa fonte se encontra na obra Apostolic Fathers, uma versão bilíngue (inglês-grego) e, ao longo do artigo, apresentaremos os trechos da carta com tradução nossa (e os recortes em inglês nas notas de rodapé), pois, assim, acreditamos expandir o acesso a outros interessados pela temática.

A I Carta de Clemente aos Coríntios é datada pela maioria dos estudiosos de meados da década de 90 d. C. Escrita em Roma por Clemente, além de dar conselhos, o autor intenta manter a unidade entre os membros da ekklesia. Segundo Barth D. Erhman (2005) a primeira menção a essa carta é feita por Dionísio de Corinto e Hegesipo alguns anos antes de 170 d. C. Para uma datação mais aproximada leva-se em consideração a abertura da carta, na qual o

\footnotetext{
${ }^{3}$ NASCIMENTO, Amanda Cristina Martins do. Entre ICoríntios e IClemente: análise das identidades cristãs em Corinto. 2019. 107f. Dissertação de Mestrado - Programa de Pós-Graduação em História Social - Universidade Estadual de Londrina, Londrina, 2019. Orientação de Monica Selvatici.

4 Durante o levantamento da bibliografia para nossa pesquisa tivemos acesso a apenas uma dissertação, intitulada: "A metáfora do corpo na I Carta de Clemente de Roma aos Coríntios (37. 5-38.1): Uma análise dialógica" (2012) de Francisco Benedito Leite e dois artigos: "Apocalipse de João e Clemente Romano como fontes para uma discussão do contexto histórico-social das comunidades cristãs do final do primeiro século" (2005) de Valtair Miranda e "São Clemente Romano e sua Carta aos Coríntios: aspectos da educação cristã" (2012) de José Joaquim Pereira Melo. Além disso, há também a dissertação de mestrado de Cynthia Santos intitulada "A Institucionalização do Cristianismo em Corinto no Século I: um Estudo Comparativo das Obras de Paulo e Clemente Romano", porém não tivemos acesso a esse trabalho.
} 
autor diz que a comunidade cristã romana havia passado por "contratempos e desgraças" (I Cl 1,1) o que levou vários pesquisadores a cogitar que I Clemente teria sido escrito no período de Domiciano, que se estendeu de 81 a 96 d. C. Durante o governo desse imperador teria havido uma perseguição motivada pela questão de que alguns indivíduos atuantes na política, mesmo alguns membros da família imperial, teriam se convertido ao cristianismo e ao judaísmo, e assim, estavam se desligando da vida pública (CHEVITARESE, 2006).

A I Carta de Clemente aos Coríntios foi um texto muito importante no cristianismo primitivo, pois foi inserido, no Códice Alexandrino, junto ao Novo Testamento e após o Apocalipse de João (KOESTER, 2005a), juntamente com grande parte da Septuaginta. Esse códice se trata de um dos quatro grandes códices unciais e é um dos mais antigos e completos, pertencentes ao século V. Além disso, foram encontradas cópias em latim, siríaco e copta, o que demonstra como foi ampla a sua circulação no Mundo Antigo.

\section{Uma Comunidade Firme, mas Insubordinada}

Ao longo do texto o autor escreveu vários elogios à comunidade coríntia; sua conduta piedosa, a fé, como sua hospitalidade era notável e até apresentou repercussão em outras comunidades (I Cl 1,2-3). A partir desse trecho podemos perceber que a comunidade de Corinto deu continuidade ao seu cristianismo, sendo inclusive modelo para outras ekklesiae; “X os deuses (COENEN; BROWN, 2000, v. 2, p. 1662-1663), que para o cristianismo se configurou como uma grande virtude concomitante a fé (COENEN; BROWN, 2000, v. 2, p.

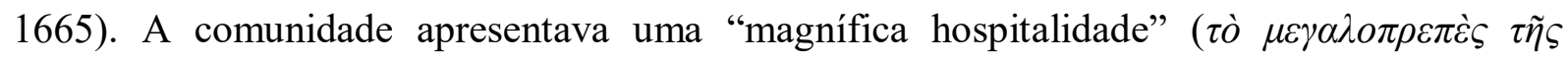
$\varphi \imath \lambda o \xi \varepsilon v i \alpha \varsigma)$ e um "conhecimento firme" ( $\alpha \varphi \alpha \lambda \tilde{\eta} \gamma \nu \tilde{\omega} \sigma l v)$.

Outro ponto relevante é um dado apresentando pelo Dicionário Internacional de Teologia do Novo Testamento (COENEN; BROWN, 2000, v. 1) que indica que dentro do cristianismo primitivo, posteriormente às cartas paulinas, o termo grego utilizado para conhecimento se modificou:

A terminologia gnóstica, portanto, foi em grande medida eliminada e substituída por outros termos, gnōsis é considerada um termo técnico para a heresia gnóstica (cf. $1 \mathrm{Tm}$ 6:20) e epgnōsis toma seu lugar, quando há referência ao conhecimento cristão (1 Tm 2:4; 2 Tm 2:25; $2: 7$; Tt 1:1) [...] a 
conversão à fé cristã pode ser descrita quase que tecnicamente como chegar ao conhecimento (epgnōsis) [...] (COENEN; BROWN, 2000, v. 1, p. 405).

O gnosticismo foi um fenômeno de cunho filosófico e religioso que surgiu no século I a. C., o qual basicamente entendia que o homem conseguiria a salvação por meio do conhecimento da natureza, da humanidade e das regiões celestiais (COENEN; BROWN, 2000, v. 1). O gnosticismo entrou em contato com diferentes práticas religiosas, o que levou ao sincretismo e a diferentes interpretações. No cristianismo compreendia a negação desse mundo, uma separação dualista entre Deus e o tempo presente (idem) e a salvação seria alcançada por meio do conhecimento individual. (idem). Resumidamente "[...] um modo de vida que surgiu da negação da validade da existência humana na história e no cosmos. Achava expressão para suas crenças através da mitologia sincretista, e se expressava na negação da ética." (idem, p. 395).

Todavia, discussões mais consistentes sobre o gnosticismo cristão ocorreram nos séculos II e III, como, por exemplo, nos escritos de Irineu de Lyon (BRAKKE, 2006). Ao longo do Novo Testamento observamos alguns indícios de pregadores, porém, em Corinto, especificamente, nada indica a presença desse fenômeno na ekklesia.

Assim, aos olhos de Clemente, nos deparamos com uma comunidade que segue corretamente os preceitos cristãos, porém que apresenta falhas estruturais que podem levar à ruína, como deixou claro o autor da carta com o objetivo de sua escrita:

[...] nós percebemos que demoramos em chamar vossa atenção para os assuntos que causam disputas entre vós, amados, envolvendo essa facção vil e profana que é estranha e estrangeira ao povo escolhido de Deus - uma facção alimentada por algumas pessoas imprudentes e obstinadas a tal passo de loucura que sua reputação venerável e renomada [...] (I Cl 1,1). ${ }^{5}$

Aqui Clemente aponta que existe uma insurreição no interior da comunidade coríntia. Contudo, o autor não deixa claro qual foi a ação cometida por esses indivíduos, isso só ocorrerá aos poucos, ao longo da epístola, conforme Clemente tenta construir seu discurso.

\footnotetext{
5 “[...] we realize that we have been slow to turn our attention to the matters causing disputes among you, loved ones, involving that vile and profane faction that is alien and foreign to God's chosen people - a faction stoked by a few reckless and headstrong persons to such a pitch of madness that your venerable and renowned reputation $[\ldots]$... (I Cl 1,1).
} 


\section{Os Presbíteros no Cristianismo do SÉculo I}

O discurso de Clemente nesse sentido aborda diferentes gêneros textuais, principalmente ligados à cultura e escrita grega. Como lembra Jaeger (2002), a concórdia pregada em seu discurso remete a textos políticos pacificadores gregos clássicos. Além disso, um dos gêneros textuais utilizados é a parênese, uma espécie de discurso moral que dispõe as obrigações de cada agente no interior da comunidade e seu modo de agir de acordo com os seus deveres, desde a atmosfera familiar em relação a esposo, esposa, filhos, até para com os dons que o cristão apresentava a serviço da ekklesia, ou mesmo com os deveres com o Estado e a sociedade à sua volta (KOESTER, 2005a).

Pois tu costumavas agir imparcialmente em tudo o que fazia, e andava de acordo com as ordenanças de Deus, submetendo-se aos seus líderes e prestando toda a devida honra àqueles que eram mais velhos [ou presbíteros] entre vós. Tu instruíste seus jovens a pensarem de forma moderada e respeitosa. Tu direcionas as mulheres a realizar todas as coisas com consciência irrepreensível, respeitosa e pura, obedientemente amando seus maridos. E tu os ensinaste a cuidar de suas casas respeitosamente, vivendo sob a regra da submissão, praticando discrição em todos os sentidos. (I Cl 1, $3)^{6}$

Além disso, como apontado acima, Leite (2012) indicou que a carta também pertence ao gênero discursivo epistolar exortativo fraternal, ou seja, Clemente adota diferentes gêneros e elementos retóricos de acordo com os seus objetivos e, também, de acordo com os seus ouvintes.

Observamos que o termo "submissão" é um elemento repetido nesse início da carta (e posteriormente) para enfatizar o que Clemente apontou como uma comunidade cristã adequada. Uma ekklesia que viva em "harmonia" entre si e com o mundo ao seu redor, de forma ordenada, sujeita a uma hierarquia ainda em construção nesse momento.

\footnotetext{
6 "For who has ever visited you and not approved your highly virtuous and stable faith? And not been astonished by your temperature and gentle piety in Christ? And not proclaimed the magnificent character of your hospitality? And not uttered a blessing for your perfect and unwavering knowledge? For you used to act impartially in all that you did, and you walked according to the ordinances of God, submitting yourselves to your leaders and rendering all due honor to those who were older [Or: presbyters] among you. You instructed your young people to think moderate and respectful thoughts. You direct women to accomplish all things with blameless, respectful, and pure conscience, dutifully loving their husbands. And you taught them to run their households respectfully, living under the rule of submission, practicing discretion in every way. (I Cl 1,3).
} 


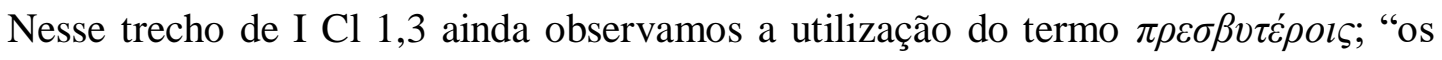
mais velhos", "embaixadores" (COENEN; BROWN, 2000, v. 1, p. 223). Mas, qual seria a função desses presbíteros nas comunidades cristãs primitivas? Como os membros poderiam alcançar tal cargo? E o que levou os fiéis coríntios a depor os presbíteros anteriores como apontou ser o motivo da escrita da carta?

No Novo Testamento observamos a utilização do termo "presbíteros" como liderança no corpus paulinum algumas vezes, mas também no texto de At 11,30, em um contexto no qual os discípulos decidem enviar auxílio para a Judeia após um período de crise: "Eles de fato o fizeram, enviando-os aos anciãos por intermédio de Barnabé e de Saulo" (grifo nosso). Segundo o Dicionário (COENEN; BROWN, 2000, v. 1), o autor emprega o termo conforme o modelo do Sinédrio das sinagogas judaicas, um conselho de anciãos que exercia a direção local.

No capítulo cinco da carta deuteropaulina de I Timóteo existe uma descrição do ofício dos presbíteros e o respeito que lhes é devido:

Os presbíteros que exercem bem a presidência são dignos de dupla remuneração, sobretudo os que trabalham no ministério da palavra e na instrução. [...] Não aceites denúncia contra um presbítero senão sob o depoimento de duas ou três testemunhas. Repreende os que pecam, diante de todos a fim de que os demais temam. [...] A ninguém imponhas apressadamente as mãos, não participes dos pecados de outrem. A ti mesmo, conserva-te puro. (I Tm 5,17, 19-20, 22)

Em outra carta, a epístola a Tito, o autor fala da instituição e quais características um indivíduo deve possuir para exercer tal cargo na comunidade:

Eu te deixei em Creta para cuidares da organização e ao mesmo tempo para que constituas presbíteros em cada cidade, cada qual devendo ser, como prescrevi, homem irrepreensível, esposo de uma única mulher, cujos filhos tenham fé e não possam ser acusados de dissolução nem de insubordinação. Porque é preciso que, sendo ecônomo das coisas de Deus, o epíscopo seja irrepreensível, não presunçoso, nem irascível, nem beberrão ou violento, nem ávido de lucro desonesto, mas seja hospitaleiro, bondoso, ponderado, justo, piedoso, disciplinado, de tal modo fiel na exposição da palavra que seja capaz de ensinar a sã doutrina como também de refutar os que a contradizem. (Tt 1,5-9) (grifo nosso)

Salientamos aqui o termo oikovó $\mu$ ov, pois seria uma palavra que designaria o administrador da casa, ou seja, o chefe da casa. Assim, além da comparação com o conselho 
de anciãos judaico, podemos estabelecer uma ligação com o pater familias, já que o local de reunião das primeiras comunidades cristãs eram as casas. Outra questão que retomamos é, conforme Campos (2011) afirmou acerca da função dos presbíteros no século I, o modelo da ekklesia que seria espelhado na constituição social da família romana, a organização e a hierarquia deveriam ser semelhantes às da casa. ${ }^{7}$

Meeks (2015) faz apontamentos nesse sentido e complementa que a liderança da assembleia estaria associada ao papel de patrono da comunidade, porém, esse tipo de institucionalização não é processo edificado, mas que irá ganhar mais força ao longo dos anos. Observamos na epístola de Clemente que nesse momento as ekklesiae ainda se configuram sob o aspecto das relações sociais que ocorrem na casa romana.

A partir disso podemos compreender que os presbíteros seriam lideranças administrativas dentro da cada ekklesia, que poderiam pregar e instruir o restante dos fiéis. Contudo, o agente deveria apresentar um comportamento irrepreensível para ser escolhido para esse papel. A própria raiz da palavra indicaria essas características necessárias, designando uma pessoa mais velha em relação a outras, associada à imagem de respeito e honra (CAMPOS, 2011).

O capital social de um agente resultaria diretamente do capital religioso dessa liderança. O que vemos em I Clemente é uma influência maior do capital social nos conflitos do que propriamente o capital religioso. O que o autor tentou em todo o seu texto foi transpor a teodiceia para a sociodiceia (BOURDIEU, 2009). Na linguagem de Pierre Bourdieu, entende-se que na função sociológica das religiões se cria uma legitimidade das estruturas sócio-políticas. Através da sua escrita, de todos os seus exemplos e comparações, Clemente fornece uma justificação das estruturas sociais no interior da comunidade.

Podemos inferir que os presbíteros não seriam pessoas eleitas pelas próprias comunidades, mas escolhidos por pregadores (ou mesmo apóstolos) que teriam um grande capital religioso dentro do movimento cristão. Como indicado na passagem da Carta a Tito, alguém externo à ekklesia deveria eleger o corpo de presbíteros, mas o que ocorreu em Corinto é que os escolhidos foram depostos posteriormente e novos agentes "tomaram" seu lugar, sem a permissão ou eleição de agentes externos.

\footnotetext{
7 Apesar do fato de que o autor dessa carta se utilizar do termo episkopos aventamos a hipótese de que nesse momento seriam cargos semelhantes no interior da assembleia cristã, como apontou Coenen e Brown (p. 230, v. 1): “Tt 1: 5, 7 torna provável que os termos presbyteros e episkopos ('bispo') sejam intercambiáveis (cf. At 20: 17, 28). Além de cumprirem certas exigências gerais pessoais e morais, têm as tarefas especiais de exortar, e de refutar os que discordam."
} 
Tome a epístola do abençoado apóstolo Paulo. O que ele escreveu para vós no início, no início de sua proclamação do evangelho? Para ter certeza, ele enviou uma carta no Espírito a respeito de si mesmo e de Cefas e Apolo, já que vós estáveis envolvidos no partidarismo. Mas esse partidarismo envolveu-vos em um pecado relativamente menor, pois vós éreis partidários de apóstolos respeitáveis e um homem aprovado por eles. (I Cl 47,1-4) ${ }^{8}$. (grifo nosso).

O partidarismo presente em Corinto no final do século I é tratado por Clemente como algo muito pior do que as facções de Paulo, Cefas, Apolo e Cristo presentes na I ${ }^{\text {a }}$ Carta de Paulo aos Coríntios, pois os três primeiros eram escolhidos, eram pregadores, os três agentes já tinham um capital simbólico acumulado. Todavia, para Clemente tal acontecimento é visto como algo mais grave, já que fere a organização e o que ele deseja estabelecer nas comunidades cristãs primitivas.

Portanto, o interesse religioso de Clemente em seu argumento é manter a comunidade coríntia unificada por meio da submissão a suas lideranças, e, ainda, legitimar uma estrutura religiosa em um nascente fenômeno religioso.

[...] a função genérica da legitimação não pode realizar-se sem que antes esteja especificada em função dos interesses religiosos ligados a diferentes posições na estrutura social [...] é função do reforço que o poder de legitimação do arbitrário contido na religião considerada pode trazer à força material e simbólica possível de ser mobilizada por este grupo ou classe ao legitimar as propriedades materiais ou simbólicas associadas a uma posição determinada na estrutura social. (BOURDIEU, 2005, p. 48).

O texto de Clemente intenta submeter os fiéis de Corinto a uma ordem que ele busca consagrar através do seu discurso, ao dar exemplos ao longo de toda a carta. No capítulo quatro o autor apresenta personagens e histórias contidos na Septuaginta, para indicar que o ciúme e a inveja são os sentimentos que podem levar à ruína de todos, não somente daqueles que possuem tais paixões, mas de todos que estão à sua volta.

O ciúme e a inveja levaram Caim a matar Abel (I Cl 4,1-7); Jacó a fugir de Esaú (I Cl 4,8); a José quase ser morto (I Cl 4,9); Moisés matou o egípcio e fugiu do faraó (I Cl 4,10); Aarão e Maria foram expulsos (I Cl 4,11); Datã e Abirão se revoltaram e foram mortos (I Cl

\footnotetext{
8 "Take up the epistle of that blessed apostle, Paul. What did he write to you at the first, at the beginning of his proclamation of the gospel? To be sure, he sent you a letter in the Spirit concerning himself and Cephas and Apollos, since you were even then engaged in partisanship. But that partisanship involved you in a relatively minor sin, for you were partisan towards reputable apostles and a man approved by them."(I Cl 47, 1-4).
} 
4,12); por causa do ciúme Saul perseguiu Davi (I Cl 4,13). Além desses, Clemente se utiliza de exemplos "presentes", as perseguições e as mortes de "[...] de nobres exemplos de nossa geração [...]” (I Cl 5,1), isto é, casos de cristãos ocorridos próximo de seu contexto:

Pedro, por causa do injusto ciúme suportou dificuldades não uma vez ou duas, mas muitas vezes; e suportado seus testemunhos ele foi para o lugar de glória que mereceu. Por causa do ciúme e das contendas Paulo mostrou o caminho para o prêmio da paciência. Sete vezes acorrentado, exilado, apedrejado, ele serviu como arauto no Oriente e no Ocidente; e ele recebeu a nobre fama por sua fé. ( $\mathrm{I} \mathrm{Cl} \mathrm{5,4-6).}{ }^{9}$

Destarte, anteriormente, em I Coríntios, Paulo também apontou em I Co 3,3-4 que havia ciúme e contendas no interior da comunidade, características que estabelecem os fiéis como "carnais" (COENEN; BROWN, 2000, v. 1). E, ainda, em I Cl 6,4, se repete a mesma

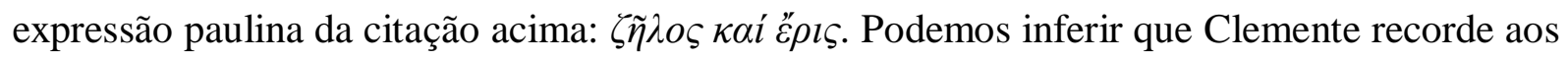
coríntios que eles já passaram por um problema semelhante, relatado pelo fundador da comunidade que, agora, seria também um exemplo maior no cristianismo.

Leite (2012, p. 60), ao indicar algumas das figuras retóricas utilizadas por Clemente, apontou que uma delas é a "anáfora": "repetição exagerada da mesma palavra como no caso de $[\mathrm{Cl}]$ 4. 8-13 onde aparece seis vezes a palavra zēlos - 16 vezes entre 4 e 6." Assim, ao reproduzir tantas vezes esse termo, Clemente tinha a intenção de enfatizar a raiz dos pecados da comunidade coríntia.

É importante salientar que nas duas citações esse sentimento é visto como algo negativo, como pecado ${ }^{10}$. Porém, enquanto Paulo registrou várias vezes a existência de brigas, discussões e contendas entre os fiéis da ekklesia, em I Clemente existe a ênfase no ciúme e na inveja. Infelizmente não sabemos se essas divisões e trocas de líderes seriam realmente um problema para a comunidade coríntia, já que não temos um documento escrito pela própria ekklesia. Ao contrário da situação relatada em I Coríntios na década de 50 d. C., na qual “pessoas da casa de Cloé” haviam procurado auxílio e informado o apóstolo Paulo sobre as

\footnotetext{
9 "There is Peter, who because of unjust jealousy bore up under hardships not just once or twice, but many times; and having thus borne his witness he went to the place of glory that he deserved. Because of jealousy and strife Paul pointed the way to the prize for endurance. Seven times he bore chains, he was sent into exile and stoned; he served as a herald in both the East and the West; and he received the noble reputation for his faith." (I Cl 5, 4$6)$.

${ }^{10}$ Como apontam Coenen e Brown (2000, v. 2, p. 2684) o termo $\zeta \tilde{\eta} \lambda o \varsigma$ apresenta dois significados no grego antigo, dependendo assim do contexto no qual está inserido. Quando está ligado a algo ou alguém no sentido positivo poderia ser entendido como "entusiasmo", "admiração" (estaria ligado com a origem do conceito em português de “zelo"). Já no sentido pejorativo seria o "ciúme", "má vontade” ou/e "inveja”.
} 
contendas ocorridas, aqui temos apenas a visão da "ekklesia que temporariamente reside em Roma”.

Podemos apenas inferir que talvez os fiéis pudessem apresentar certa autonomia, já que a discussão sobre lideranças não seria a primeira vez que ocorria. Além disso, com o histórico apresentado pela comunidade coríntia podemos supor que alguns de seus fiéis tinham o interesse religioso em manter um capital de autoridade (BOURDIEU, 2009, p. 58) para si. E, como aponta Bourdieu, para isso é necessária força material e simbólica (idem, p. 58), o que Clemente poderia não apresentar, mas os membros coríntios poderiam possuir por estarem inseridos na comunidade e por exibirem um "conhecimento firme". Mesmo com esses eventos a comunidade continuava a prosperar (como o próprio autor destacou no início da carta).

James Walters (2005), em seu artigo Civic Identity in Roman Corinth and Its Impact on Early Christians, ao investigar os conflitos entre facções citados pelo apóstolo Paulo na I ${ }^{\mathrm{a}}$ Carta aos Coríntios, apontou que um dos motivos para essa comunidade apresentar problemas internos seria a ausência de conflitos com não cristãos. Em seu texto Walters apresentou como contraponto o caso dos cristãos-judaizantes citados pelo apóstolo Paulo na Ia Carta aos Tessalonicenses, mas também podemos pensar em perseguições por autoridades locais. Como já dissemos, em nenhum momento, tanto em Clemente ou mesmo nas cartas do apóstolo Paulo, existem menções a perseguições. Pelo contrário, Clemente afirmou em diversos trechos da epístola a continuidade fundamentada da fé cristã: "Plena reputação e prosperidade vos foi concedida [...]", e continua o autor: "Daí nasceram o ciúme e a inveja, a discórdia e a revolta, a perseguição e a desordem, a guerra e o cativeiro." (I Cl 3,1-2).

Walters ainda afirma que essa ausência de conflitos:

[...] resultou em uma mudança na identidade cívica dos coríntios romanos [...] A evolução da identidade cívica criou uma ambiguidade na identidade religiosa da cidade, deixando a indivíduos e grupos uma maior liberdade para definir sua própria identidade religiosa. (WALTERS, 2005, p. 416) ${ }^{11}$.

Dessa maneira, podemos supor que a comunidade coríntia poderia buscar uma autonomia na escolha de suas lideranças. Como a comunicação entre Clemente e a assembleia

11 " [...] result of the changing civic identity of Roman Corinth [...] This evolution of civic identity created ambiguity in the city's religious identity, leaving individuals and groups more freedom to define their own religious identities." 
de Corinto se deu após certo intervalo de tempo (em razão das perseguições relatadas), os fiéis coríntios se mantiveram de forma independente, sem intervenções externas, mesmo aquelas de outras ekklesiae.

Todavia, para Clemente e a comunidade cristã romana, a realidade social e a religiosa eram diferentes. Por estar localizada no centro do poder do Império, possivelmente seus membros não poderiam causar alardes e escândalos, para não sofrer perseguições e, mesmo assim, em diferentes momentos e por diferentes motivos isso ocorria. O que levaria uma crítica às mudanças, como em I Clemente 7,2 - trecho no qual o autor afirma que a alternância de lideranças não passa de “[...] pensamentos vazios e frívolos [...]” que deveriam ser abandonados e deveria se voltar para a prática da "[...] famosa e venerável norma de nossa tradição". A tradição mencionada nesse trecho poderia ser a relatada em Tt 1,5-9 e em I Cl 47, 1-4, que não seria algo bem estabelecido, como viria a ser nos séculos II e III, mas o princípio da hierarquização da igreja cristã primitiva, algo que Clemente tentou justificar como sempre presente através dos anseios divinos na história da humanidade.

\section{A EkKLEsia de Roma À Frente das Comunidades Cristãs?}

Joaquim de Melo em seu artigo "São Clemente Romano e sua Carta aos Coríntios: aspectos da educação cristã" (2012) ao se atentar à questão da paideia cristã afirma que o texto de I Clemente já assinala para a igreja cristã primitiva de Roma como um grupo “intervencionista”. E, ainda, Melo também aponta que a carta de Clemente já representa um cristianismo mais centralizador advindo de Roma, que se sobressairia nos anos seguintes.

Ludmila Campos (2011) vai ao encontro desse pensamento em sua dissertação de mestrado intitulada "'Um Bispo, um Deus, uma Ekklesia': A formação do episcopado monárquico no Alto Império". A autora afirma que o texto de Clemente Romano caminha para um "episcopado monárquico" advindo da sucessão apostólica, ratificada posteriormente por Inácio de Antioquia (Campos, 2011).

Contudo, discordamos de tais autores nessa questão. O que observamos na comparação entre as duas comunidades é que em Corinto temos uma agremiação que se assemelharia à raiz do conceito de ekklesia, isto é, uma assembleia popular de cidadãos que, em suas reuniões, poderia decidir mudanças sociais e políticas internas e externas (COENEN; BROWN, 2000), diferentemente da comunidade cristã romana, que refletiria melhor o modelo 
de um collegium (JEFFERS apud LEITE, 2012), da mesma forma que as sinagogas judaicas no território do Império (MEEKS, 2015).

Portanto, no nosso entendimento, a conjuntura apresentada pelas duas comunidades representa a diversidade de ideias e práticas religiosas que surgiram no cristianismo primitivo, de acordo com o contexto social das localidades a que pertenciam. Não encontramos na fala de Clemente uma imposição de sua autoridade à ekklesia coríntia, o que observamos na linguagem bourdieusiana, é a construção de uma realidade social (BOURDIEU, 1996, p. 205), algo correto e que deveria ser praticado e imitado.

Guarinello (2009) afirma que o Império Romano nunca foi uma sociedade homogênea, mas sim, um agrupamento de diferentes sociedades, uma população com práticas e pensamentos bastante diversos. Assim, “cidadãos e não cidadãos, livres e não livres, ricos e pobres, letrados e iletrados, proprietários de terras e trabalhadores manuais, riqueza móvel e riqueza imóvel [...]" (GUARINELLO, 2009, p. 151) formavam o mundo social romano, e no cristianismo primitivo observamos pessoas dessas diferentes clivagens. Isto levou a diferentes conflitos em diferentes contextos, sejam eles internos ou o choque com um cristianismo hierarquizado pregado por Clemente.

Ademais, ao longo do seu discurso Clemente não se utiliza do seu capital de autoridade, em nenhuma ocasião o autor se apresenta como uma liderança ou ao menos exprime o pensamento de que a ekklesia de Roma seria superior à comunidade coríntia. Aqui concordamos com a visão de Leite $(2012$, p. 59) de que o texto explicita um tom de igualdade entre as comunidades:

O tom da carta parece ser de um irmão quando fala com outro, pois, como já nos referimos, a carta não está no singular, mas no plural, por isso, há certa exclusividade em vista das demais cartas que fazem parte do cânon e mesmo em vista das cartas de Inácio de Antioquia. Visto que em I Clem não parece haver nível hierárquico que diferencie os emissários: Clemente e os crentes de Roma; em vista do narratário ou remetente que é a comunidade de Corinto.

A finalidade do escrito de Clemente é manter a união fraterna dos fiéis coríntios, pois segundo ele, as autoridades religiosas instituídas foram depostas por membros mais jovens (I Clemente 47,6). Dessa maneira, a carta é escrita sob os signos do exemplo e a submissão. Contudo, a submissão não seria entre as ekklesiae, mas a sujeição aos presbíteros anteriormente constituídos. 
Melo (2012, p. 188) também indica que a carta poderia ser entendida como uma enteuxis:

[...] na linguagem jurídica, designava uma petição dirigida ao rei, enquanto fonte do direito, para que ele formulasse juízo sobre uma causa. Admitindose esse uso, consabidamente técnico, pode-se ver na carta um convite para que a própria comunidade se fizesse juiz da "revolta" no interesse da "paz" (MORESCHINI; NORELLI, 1996), o que deveria particularizar uma comunidade cristã e, assim, tornar-se exemplo para as comunidades irmãs e para o mundo chamado "pagão".

Ou seja, nesses apontamentos Clemente indica que o interesse do grupo deve se sobressair à vontade individual. Como apontou Melo acima, Clemente Romano age como juiz, sendo personagem de fora do círculo coríntio, então ele observa e julga sob a ótica de que a comunidade como o grande corpo de Cristo deve agir conjuntamente. Um olhar "técnico" de um indivíduo que não está presente na comunidade, ou, nas palavras de Leite (2012, p. 59), um estilo fraternal devido à ausência da hierarquia. E, como apontamos anteriormente, os "ciúmes e a inveja" indicados pelo autor são causas dessa desordem que poderia levar à queda de toda a comunidade.

\section{A Submissão como Condição de uma Comunidade Organizada.}

A recomendação dada por Clemente de seguir as lideranças estabelecidas é o resultado que ele esperava que todos reproduzissem, o que poderíamos identificar como um "habitus cristão romano". Chamamos de "habitus cristão romano", pois, ao que nos parece, isso está presente ao longo da carta, em arquétipos de fiéis no passado, personagens do Antigo Testamento, e ainda, nos modelos de cristãos martirizados, indicando como exemplos a serem seguidos pelos coríntios.

Em sua mensagem Clemente também apontou que cada cristão recebe um dom de Deus, seguindo essa lógica, cada dom deve ser exercido a serviço da comunidade. Por conseguinte, havia cristãos que deveriam liderar, outros deveriam segui-lo, uma vez que era a vontade divina se realizando na ekklesia. Os fiéis deveriam ser submissos às lideranças da comunidade (I Cl 1,3); submissos à palavra de Deus (I Cl 13,3); ou seja: “[...] em Cristo Jesus, e deixe que cada pessoa sujeita ao seu vizinho, de acordo com o dom da graça que recebeu.[...]" (I Cl 38,1). 
Voltando à passagem de $\mathrm{I} \mathrm{Cl} \mathrm{1,3,} \mathrm{notamos} \mathrm{a} \mathrm{caracterização} \mathrm{por} \mathrm{parte} \mathrm{de} \mathrm{Clemente} \mathrm{dos}$ papéis dos fiéis dentro da comunidade cristã, essa ação também estabelece uma relação de submissão entre fiéis no interior da ekklesia: as mulheres para com seus maridos, o restante da comunidade para com os seus anciãos, enfim, novamente salientamos que o que o autor aventa é uma organização hierárquica no interior da comunidade, o interesse do grupo deve se sobressair à vontade individual.

$\mathrm{Na}$ fala de Clemente Romano, observaremos que as sociodiceias descritas advêm de uma teodiceia maior, que seria uma ordem divina, e que os coríntios precisavam se inserir nesse conjunto. Observamos que a experiência religiosa da comunidade cristã de Roma estabeleceu como sagrada essa conjuntura, sujeita a uma hierarquia e normas; a subversão disso, as rixas e dissensões que surgiram em Corinto, por exemplo, significariam a desordem, o caos.

Assim:

O grande Criador e Senhor de tudo ordenou todas essas coisas para que existissem em paz e concórdia, já que deseja o bem de todas as criaturas, mostrando-se generoso demais em relação a nós que nos refugiamos em sua misericórdia por nosso Senhor Jesus Cristo. (I Cl 20,11) ${ }^{12}$.

Dessa maneira, para Clemente Romano, a ordem estabelecida desde os apóstolos (como ele afirmou na passagem citada anteriormente de I $\mathrm{Cl} 42,4$ ) possivelmente instituída por meio de algum tipo de ritual, era a representação da organização divina. Em linguagem bourdieusiana, ele está utilizando de certa tradição (inventada ou não) para legitimar seu discurso, buscando angariar capital religioso (autoridade).

Os céus movem-se por Sua disposição e lhe submetem na paz. O dia e a noite percorrem o caminho por Ele demarcado, sem jamais se impedirem mutuamente. Sol, lua e demais astros giram conforme Sua determinação, em harmonia e sem desvio algum pelas órbitas prescritas a cada um deles. A terra, submissa à Sua vontade, fecunda nas estações próprias e provém sustento aos homens, animais e todos os seres vivos, sem se rebelar nem se afastar da ordem por Ele desejada. [...] O mar imenso, encerrado dentro da bacia que o contém, não ultrapassa os limites a ele impostos, mas, assim como lhe foi ordenado, o obedece. Pois foi Ele quem disse: "Até aqui chegarás e tuas ondas se quebrarão em ti mesmo". O oceano, intransponível

12 "The great Creator and Master of all appointed all these things to be in peace and harmony, bringing great benefits to all things, but most especially to us, who flee to his compassion through our Lord Jesus Christ." (I Cl 20,11). 
aos homens, bem como os mundos atrás dele, ordenam-se pelas mesmas leis do Senhor. As estações da primavera, verão, outono e inverno se sucedem umas às outras em paz. (I Cl 20,1-3, 6-9) ${ }^{13}$

Até mesmo a natureza encontra-se sob o jugo divino, porque foi criada por Deus, assim a hierarquia defendida por Clemente serviria como um ritual que atualizaria essa organização dentro das comunidades cristãs. No entanto, ainda em termos de hipóteses, em meio a um território de conflito (troca de líderes), Clemente elabora um discurso que busca conferir legitimidade às suas práticas, angariando (ou não) os fiéis.

Essa argumentação que Clemente Romano dirige aos coríntios também é perpassada pela ideia de Bourdieu de alquimia ideológica, já que além de justificar uma ordenação social também apresenta uma organização presente na natureza:

[...] a religião contribui para a imposição (dissimulada) dos princípios de estruturação da percepção e do pensamento do mundo e, em particular, do mundo social, na medida em que impõe um sistema de práticas e de representações cuja estrutura objetivamente fundada em um princípio de divisão política apresenta-se como a estrutura natural-sobrenatural do cosmos (BOURDIEU, 2009, p. 33-34).

A autoridade imposta por Clemente no nosso entendimento se assemelha à convenção sociocultural ditada pelo Império Romano aos povos que estavam sob seu domínio. O Império abarcava uma grande diversidade de culturas e, concomitante a isso, uma grande variedade de cultos e práticas religiosas e culturais. Porém, a cultura do "outro" era tolerada apenas enquanto não causasse desordem na sociedade romana, e isso também se reflete nas crenças religiosas. A pax deorum era garantida através dos rituais de maneira ordenada e segura (ROSA, 2006, p. 146). Então, da mesma maneira que havia uma organização sacerdotal bem estabelecida que garantia a manutenção dos cultos romanos ${ }^{14}$, e um corpo político estruturado por meio de um modelo pessoal de poder romano, uma "monarquia republicana" conforme a

\footnotetext{
13 "The heavens, which move about under his management, are peacefully subject to him. Day and night complete the racecourse laid out by him, without impeding one another in the least. Sun and moon and the chorus of stars roll along the tracks that have been appointed to them, in harmony, never crossing their lines, in accordance with the arrangement he has made. [...] The basin of the boundless sea, established by his workmanship to hold the waters collected, does not cross its restraining barriers, but acts just as he ordered. For he said, 'You shall come this far, and your waves shall crash down within you.' The ocean, boundless to humans, and the worlds beyond it are governed by the same decrees of the Master. The seasons - spring, summer, fall, and winter - succeed one another in peace." (I Cl 20,1-3, 6-9).

${ }^{14}$ Claudia Beltrão da Rosa em seu artigo "A Religião na Urbs" (2006, p. 143) apresenta um quadro com os "Colégios Sacerdotais Romanos", os principais grupos de lideranças religiosas romanas, que demonstra a organização e as mudanças a partir de Augusto.
} 
análise de Norma M. Mendes (2006), a comunidade cristã romana parece também intentar estabelecer uma ordem hierárquica.

No capítulo trinta e sete Clemente apresenta sua admiração pela ordem romana:

E assim, irmãos, com toda ânsia, façamos a batalha como soldados sob seus comandos irrepreensíveis. Considere aqueles que soldado sob nossos próprios governantes, como eles realizam o que lhes é exigido com tal ordem, hábito e submissão. Pois nem todos são generais ou comandantes com mais de mil soldados, nem cem, nem cinquenta, e assim por diante. Mas cada um, de acordo com sua própria posição, realiza o que é ordenado pelo rei e pelos líderes. Aqueles que são importantes não podem sobreviver sem os humildes nem os humildes sem o grande. Há uma certa combinação em todas as coisas, e isso prova ser útil para elas. $(\mathrm{I} \mathrm{Cl} 37,1-3)^{15}$

Retomando o conceito de presbyteros nesse contexto ao se remeter a características culturais, os mais velhos eram instituídos como lideranças e, ainda, "sendo a hierarquia eclesiástica um espelho da hierarquia doméstica e social romana." (CAMPOS, 2011, p. 121). Ou seja, a estrutura do mundo social romano era uma instituição exemplar que poderia ser seguida dentro das comunidades cristãs primitivas.

Aqueles que se "revoltaram" contra essa organização deveriam se retirar da comunidade, por sua própria vontade, como "sacrifícios", isto é, pelo bem maior:

Quem, portanto, entre vocês é nobre? Ou compassivo? Ou cheio de amor? Que, além do que se diga, "Se eu for a causa da facção, conflitos e cismas, partirei; Eu irei onde quiser e faço o que é comandado pela congregação. Só permita que o rebanho de Cristo esteja em paz com os presbíteros que foram nomeados." Quem agir assim se tornará eminente em Cristo e será bemvindo em todos os lugares. "Para a terra e tudo o que nela reside, pertence ao Senhor". Aqueles que realizaram seu dever cívico a Deus, sem arrependimentos, fizeram essas coisas e continuarão a fazer então. (I Cl 54, $1-4)^{16}$.

\footnotetext{
15 "And so, brothers, with all eagerness let us do battle as soldiers under his blameless commands. Consider those who soldier under our own leaders, how they accomplish what is demanded of them with such order, habit, and submission. For not all are commanders-in-chief or commanders over thousand troops, or hundred, or fifty, and so on. But each one, according to his own rank, accomplishes what is ordered by the king and the leaders." (I Cl 37, 1-3).

16 "Who, therefore, among you is noble? Or compassionate? Or filled with love? Let than one say, "If I am the cause of faction, strife, and schisms, I will depart; I will go wherever you wish and do what is commanded by the congregation. Only allow the flock of Christ to be at peace with the presbyters who have been appointed." The one who does this will have made himself eminent in Christ and will be welcomed everywhere. "For the earth, and all that is in it, belongs to the Lord." Those who have performed their civic duty to God, without regrets, have done these things and will continue to do them." (I Cl 54, 1-4).
} 
Porém, antes Clemente apontou que o caminho para esses agentes seria a "conversão" (I Cl 7,4). O termo grego antigo empregado pelo autor nesse e em trechos posteriores é $\mu \varepsilon \tau \alpha v o ́ l \alpha$, que significaria "mudança de opinião" (COENEN; BROWN, 2000, p. 419), que quando utilizada no Novo Testamento enfatiza a mudança de pensamento e não na mudança física (idem, p. 420). Essa transformação transpassaria por pensamentos totalmente opostos, já que Clemente faz uma ligação entre a conversão e a submissão nas passagens seguintes. Novamente ao repetir o artifício dos exemplos a serem seguidos, ele aponta como Henoc sendo submisso foi arrebatado (I Cl 9,3); Noé conseguiu salvar a todos na arca por meio da sua fidelidade ( $\mathrm{Cl}$ 9,4); Abraão ao obedecer e se submeter às promessas se tornou amigo de Deus (I Cl 10). E assim Clemente continua a relatar exemplos de personagens até o capítulo doze.

Do capítulo treze ao dezesseis, Clemente passa a uma série de "dizeres" ou "ditos", expressões que são retiradas de escritos do Antigo Testamento como também das cartas paulinas. Tudo isso com o objetivo de estabelecer a ordem da comunidade, trabalhar a correção que os fiéis de Corinto devem receber e demonstrar que a hierarquia estabelecida anteriormente deve ser seguida: "E assim é o correto e sagrado para nós obedecer a Deus, irmãos, ao invés de seguir aqueles que instigam a um sujo ciúme com arrogância e desordem." (I Cl 14,1).

Já a partir do capítulo dezessete o autor retoma a descrever os exemplos do Antigo Testamento, porém, ressalta que esses indivíduos foram reconhecidos por Deus graças ao arrependimento e a sua humildade. Após citar exemplos como Elias, Abraão e Davi, Clemente finaliza essa reflexão com a seguinte ponderação:

A humildade e a modesta obediência de tantas pessoas com uma tão forte reputação melhoraram não apenas a nós, mas também às gerações que vieram antes de nós - na verdade, a todos aqueles que receberam as declarações de Deus em temor reverente e verdade. E assim, uma vez que compartilhamos tais atos numerosos, grandiosos e gloriosos, devemos avançar para a meta da paz que nos foi entregue desde o princípio. (I $\mathrm{Cl}$ $19,1-2)^{17}$.

\footnotetext{
17 "The humility and obedient lowliness of so many people with such a strong reputation have improved not only us, but also the generations that came before us - indeed all those who received the sayings of God in reverential awe and truth. And so, since we have shared in such numerous, great, and glorious deeds, we should forge ahead to the goal of peace that has been delivered to us from the beginning." (I Cl 19, 1-2).
} 
Outro ponto a se ressaltar em todos esses exemplos é que todos são lembrados por suas obras, e estes são compartilhados por todos, como afirmou Clemente na passagem acima. Leite (2012, p. 65) afirma que isso ocorre, uma vez que existiu uma dificuldade no entendimento da palavra "fé" em sua passagem da língua grega para o latim: "[...] uma possível dificuldade linguística que o autor tivera com o termo pístis, pois em um mundo de fala latina, o termo se torna ambíguo, dado que primeiramente traduzia-se por fides [fidelidade patronal, tradicional nos relacionamentos verticais do Império Romano] [...]”. Leite ainda afirma que, dessa maneira, em I Clemente, a fé poderia ser traduzida como uma “confiança espiritualizada em Deus”, confiança esta que deveria ser depositada também nas autoridades escolhidas.

Destarte, toda a repetição de tais paradigmas intenta efetivar uma eficácia simbólica e propor aos fiéis essa hierarquização como concepções naturais (OLIVEIRA, 2003), que já existiram. Em Paulo a fé seria o recebimento da mensagem de salvação, a crença na morte e ressurreição de Cristo (tantas vezes lembrada pelo apóstolo, como, por exemplo, em I Co 15) assim, resultando em um comportamento baseado na boa nova (COENEN; BROWN, 2000, p. 816). Já em Clemente, o termo é:

[...] compreendido a partir das relações sociais do século I e da evolução semântica ocorrida devido a sua utilização pelos cristãos dos primeiros séculos, passa a designar fidelidade e submissão à instituição cristã na descrição dos Exemplos do Antigo Testamento, próximo ao significado do termo fides (9-12) uma "boa obra", ao lado de outras [...] (LEITE, 2012, p. $66)$.

\section{CONSIDERAÇÕES FINAIS}

Observamos ao longo de nossa análise que Clemente intenta encerrar os fiéis coríntios em um modelo de cristianismo que, para ele, seria o correto. Sua concepção de ekklesia sob a ótica de uma submissão, obediência e humildade se contrapõe à situação vivida na comunidade de Corinto daquele momento, que, segundo o próprio autor, estava dividida por interesses pessoais. Todavia, ao repetir tantos modelos a serem seguidos, ele exalta uma submissão primeira a Deus e sua vontade, uma entrega total aos anseios divinos (no capítulo dez da carta se fala do exemplo de como Abraão ofereceu seu filho em sacrifício, obedecendo a um pedido divino). Portanto, a hierarquização presente no interior da comunidade cristã 
primitiva seria uma ordenança divina, a qual não importa que lideranças fossem escolhidas, mas que o restante da ekklesia deveria seguir.

A hierarquização nesse momento inicial da comunidade cristã consiste em uma sucessão de categorias, buscando uma configuração na qual cada cristão deveria sua submissão a alguém; os jovens aos mais velhos, os fiéis às lideranças instituídas, as mulheres aos seus maridos. Embora ainda estejamos longe de uma hierarquia religiosa plenamente definida, notamos na fala de Clemente que o cristianismo já caminhava para essa direção. $\mathrm{O}$ autor cria em seu texto uma comunidade idealizada, exemplo para todas as igrejas cristãs primitivas, na qual apenas a conduta do grupo revoltoso constitua uma anomalia que pode levá-los até a exclusão do Reino de Deus (I Clemente 57,2).

Observamos até mesmo o contraste entre essas duas ekklesiae (Corinto e Roma), e que as distinções por se encontrarem em diferentes meios sociais também se refletiam na constituição das identidades dessas comunidades religiosas. As comunidades cristãs primitivas se desenvolveram em um constante processo de interações culturais, sua estruturação e suas práticas estavam sujeitas a modificações e negociações com o ambiente em que se encontravam. Assim, as representações e as condutas expressadas por seus membros demonstram as diferentes significações que diferentes grupos criaram sobre o modo de "ser" cristão.

\section{REFERÊNCIAS}

\section{FONTES}

BÍBLIA DE JERUSALÉM. São Paulo: Paulus, 2002.

CLEMENT. First Letter of Clement. In: The Apostolic Fathers I. Edited and Translated: Bart D. Ehrman. The Loeb Classical Library. Cambridge, Massachusetts: Harvard University.

\section{BIBLIOGRAFIA}

BOURDIEU, Pierre. A Economia das Trocas Simbólicas. Coleção Estudos, dirigida por J. Guinsburg, $6^{\text {a }}$ ed., São Paulo: Perspectiva, 2009. 
BOURDIEU, Pierre. Razões Práticas: sobre a teoria da ação. 11 ed. Tradução: Mariza Corrêa; Campinas: Papirus, 1996.

CAMPOS, Ludimila Caliman. "Um Bispo, um Deus, uma ekklesia": A formação do episcopado monárquico no Alto Império. Dissertação (Mestrado em História) 2011. 203f, Universidade Federal do Espírito Santo, Espírito Santo, 2011. Disponível em: http://repositorio.ufes.br/bitstream/10/3458/1/tese_4627_Ludimila_Caliman_Campos.pdf. Acessado em: 15 jan. 2018.

COENEN, L.; BROWN, C. Dicionário Internacional de Teologia do Novo Testamento, v. 1, São Paulo: Vida Nova, 2000.

COENEN, L.; BROWN, C. Dicionário Internacional de Teologia do Novo Testamento, v. 2, São Paulo: Vida Nova, 2000.

\section{CHEVITARESE, André L. Cristianismo e Império Romano. In: Repensando o Império}

Romano: perspectiva socioeconômica, política e cultural. Rio de Janeiro: Mauad, Vitória, ES: EUFES, 2006, p. 161-173.

EHRMAN, Bart D. Introduction. In: The Apostolic Fathers I. Edited and Translated: Bart D. Ehrman. The Loeb Classical Library. Cambridge, Massachusetts: Harvard University Press, 2005, p. 18-33.

GUARINELLO, Norberto Luiz. Império Romano e Identidade Grega. In: Funari, P. P. A., SILVIA, M. A. de O. (orgs.). Política e identidades no mundo antigo. São Paulo: Annablume; Fapesp, 2009, p. 147-161.

JAEGER, Werner. Cristianismo Primitivo e Paideia Grega. Tradução: Terese Louro Pérez; Lisboa: Edições 70, 2002.

KOESTER, Helmut. Introdução ao Novo Testamento - volume 2: História e Literatura do Cristianismo Primitivo. São Paulo: Paulus, 2005

LEITE, Francisco Benedito. A metáfora do corpo na I Carta de Clemente de Roma aos Coríntios $(37,5$ - 38, 1): uma análise dialógica. Dissertação (Mestrado em Ciências da Religião) 2012. 162f. Universidade Metodista de São Paulo, São Bernardo do Campo, 2012.

MEEKS, Wayne A. Os Primeiros Cristãos Urbanos: O mundo social do apóstolo Paulo. Tradução: I. F. L. Ferreira, Santo André: Academia Cristã/Paulus Editora, 2015.

MELO, José Joaquim Pereira. São Clemente Romano e sua Carta aos Coríntios: aspectos da educação cristã. Revista Brasileira de História das Religiões, ANPUH, ano V, n. 13, Maio 2012. Disponível em:

http://www.periodicos.uem.br/ojs/index.php/RbhrAnpuh/article/view/30258/15856. Acessado em: 17 dez. 2017.

MENDES, Norma Musco. O Sistema Político do Principado. In: Silva, G. V.; Mendes, N. M.(orgs). In: Repensando o Império Romano: Perspectivas Socioeconômicas, Política e Cultural. Rio de Janeiro: Mauad; Vitória, ES: EUFES. 2006, p. 21-51.

MIRANDA, Valtair A. Apocalipse de João e Clemente Romano como fontes para uma discussão do contexto histórico-social das comunidades cristãs do final do primeiro século. Rev. Oracula - Revista Eletrônica de Pesquisas em Apocalíptica Judaica e Cristã da Universidade Metodista de São Paulo, v.1, n.1, 2005. Disponível em: 
<https://www.metodista.br/revistas/revistasims/index.php/oracula/article/viewFile/5926/4796>. Acessado em: 06 abr. 2018.

OLIVEIRA, Pedro A. Ribeiro de. A teoria do trabalho religioso em Pierre Bourdieu. In: TEIXEIRA, Faustino (Org.). Sociologia da religião. Petrópolis, RJ: Vozes, 2003. p. 177-197.

ROSA, Claudia B. da. A Religião da Urbs. In: Silva, G. V.; Mendes, N. M.(orgs).

Repensando o Império Romano: Perspectivas Socioeconômicas, Política e Cultural. Rio de Janeiro: Mauad; Vitória, ES: EUFES. 2006, p. 137-159.

WALTERS, James. Civic Identity in Roman Corinth and Its Impact on Early Christians. In: SCHOWALTER, D.N.; FRIESEN, S.J. (orgs.). Urban Religion in Roman Corinth:

Interdisciplinary Approaches. Massachusetts, Harvard University Press, 2005. p. 397-418. 